\title{
Dye Sensitization in the Visible Region for Low-Bandgap Polymer Solar Cells
}

\section{$\operatorname{AUTHOR}(S):$}

Wang, Y.; Zheng, B.; Tamai, Y.; Ohkita, H.; Benten, H.; Ito, S.

\section{CITATION:}

Wang, Y. ... [et al]. Dye Sensitization in the Visible Region for Low-Bandgap Polymer Solar Cells. Journal of the Electrochemical Society 2014, 161(7): D3093-D3096

ISSUE DATE:

2014-02-15

URL:

http://hdl.handle.net/2433/189421

RIGHT:

(C) 2014 The Electrochemical Society. 


\title{
Dye Sensitization in the Visible Region for Low-Bandgap Polymer Solar Cells
}

\author{
Yanbin Wang, ${ }^{\mathrm{a}}$ Bo Zheng, ${ }^{\mathrm{a}}$ Yasunari Tamai, ${ }^{\mathrm{a}}$ Hideo Ohkita, ${ }^{\mathrm{a}, \mathrm{b}}$ Hiroaki Benten, ${ }^{\mathrm{a}}$ \\ and Shinzaburo Ito ${ }^{\mathrm{a}, \mathrm{z}}$ \\ ${ }^{a}$ Department of Polymer Chemistry, Graduate School of Engineering, Kyoto University, Nishikyo, \\ Kyoto 615-8510, Japan \\ ${ }^{b}$ Japan Science and Technology Agency (JST), PRESTO, Kawaguchi, Saitama 332-0012, Japan
}

\begin{abstract}
We have fabricated ternary blend solar cells by incorporating a wide-bandgap molecule, tris[4-(5-dicyanomethylidenemethyl-2thienyl)phenyl]amine (TDCV-TPA), into a binary blend of a low-bandgap polymer, poly[2,3-bis-(3-octyloxyphenyl)quinoxaline5,8-diyl-alt-thiophene-2,5-diyl] (PTQ1), and a fullerene derivative (PCBM) in order to enhance exciton generation and hence charge generation in the visible region. The ternary blend solar cells exhibited large external quantum efficiency (EQE) in the visible range as well as in the near-IR range. As a result, the short-circuit current density $\left(J_{\mathrm{SC}}\right)$ was improved by more than $20 \%$.

(C) 2014 The Electrochemical Society. [DOI: 10.1149/2.015407jes] All rights reserved.
\end{abstract}

Manuscript submitted February 17, 2014; revised manuscript received April 25, 2014. Published May 13, 2014. This paper is part of the JES Focus Issue on Electrochemical Processing and Materials Tailoring for Advanced Energy Technology.

Polymer solar cells have attracted increasing attention because of their unique advantages such as light weight, flexible, and low-cost and high-throughput processing for large-area devices. ${ }^{1-3}$ Currently, a power conversion efficiency of more than $10 \%$ has been reported. ${ }^{4,5}$ This remarkable progress is mainly due to intensive developments of various low-bandgap polymers that can harvest the solar light in the near-IR region. ${ }^{6-10}$ Low-bandgap polymers have an absorption band in the near-IR region but an absorption window in the visible region at the same time because of their narrow absorption bandwidth. In other words, it would be difficult to harvest the solar light over a wide wavelength range by using low-bandgap polymers alone. For further improvements, it is necessary to harvest much more photons not only in the visible but also near-IR region. In order to overcome this limitation, ternary blend solar cells have been proposed in recent years. ${ }^{11-25}$ Previously, we have demonstrated near-IR dye sensitization of polymer/fullerene solar cells, in which the light-harvesting efficiency in the near-IR region can be improved by incorporating a near-IR dye into binary blend solar cells based on a wide-bandgap polymer and a fullerene derivative. ${ }^{11}$

Herein, we study dye sensitization in the visible region for low-bandgap polymer solar cells based on poly[2,3-bis-(3octyloxyphenyl)quinoxaline-5,8-diyl-alt-thiophene-2,5-diyl] (PTQ1) and phenyl- $\mathrm{C}_{61}$-butyric acid methyl ester (PCBM). For dye sensitization in the visible region, a wide-bandgap molecule tris[4(5-dicyanomethylidenemethyl-2-thienyl)phenyl]amine (TDCV-TPA) was incorporated into low-bandgap binary blends of PTQ1/PCBM. As a result, the light-harvesting efficiency was improved in the visible region and hence the short-circuit current density $J_{\mathrm{SC}}$ of ternary blend solar cells was increased by $24 \%$ compared to that of control solar cells based on PTQ1/PCBM binary blends. We discuss the sensitization mechanism in PTQ1/PCBM/TDCV-TPA solar cells in terms of dye location in the ternary blend films.

\section{Experimental}

Device fabrication. - Three kinds of materials as shown in Figure 1 were employed for ternary blend films: PTQ1 (Solarmer, number-averaged molecular weight, $\left.M_{\mathrm{n}} \approx 28,000 \mathrm{~g} \mathrm{~mol}^{-1}\right), \mathrm{PCBM}$ (Frontier Carbon, E100H), and TDCV-TPA (Aldrich). Ternary blend solar cells were fabricated as follows. First, indium/tin oxide (ITO)coated glass substrates ( $10 \Omega$ per square) were washed by ultrasonication in toluene, acetone, ethanol for $15 \mathrm{~min}$, dried with nitrogen gas, and then cleaned with a UV-O 3 cleaner (Nippon Laser \& Electronics NL-UV253S) for $30 \mathrm{~min}$. A thin layer $(\sim 40 \mathrm{~nm})$ of poly $(3,4-$

${ }^{\text {z} E-m a i l: ~ s i t o @ p h o t o . p o l y m . k y o t o-u . a c . j p ~}$ ethylenedioxythiophene):poly(4-styrenesulfonate) (PEDOT:PSS; H. C. Starck PH500) was spin-coated onto the cleaned substrates at a spin rate of $3000 \mathrm{rpm}$, and the layer was dried at $140{ }^{\circ} \mathrm{C}$ for $10 \mathrm{~min}$ in air. The solution of PEDOT:PSS was filtered by using a $0.45 \mu \mathrm{m}$ PTFE syringe filter prior to the spin-coating. A ternary blend active layer of PTQ1/PCBM/TDCV-TPA was prepared by spin-coating on the PEDOT:PSS-coated ITO substrate at a spin rate of $1000 \mathrm{rpm}$ for 60 s. The ternary blend solution was prepared as follows: PTQ1, PCBM, and TDCV-TPA were dissolved in $o$-dichlorobenzene at a concentration ratio of $20: 40: 2 \mathrm{mg} \mathrm{mL}^{-1}$ ([TDCV-TPA] $=3.2 \mathrm{wt} \%$ ) and then the mixed solution was stirred at $40{ }^{\circ} \mathrm{C}$ overnight. Note that the dye composition was optimized in the range from 1.6 to $4.8 \mathrm{wt} \%$ and the best performance was obtained at $3.2 \mathrm{wt} \%$. An electrode of $\mathrm{Ca} / \mathrm{Al}$ layer $(15 / 70 \mathrm{~nm})$ was deposited in sequence on top of the active layer at $2.5 \times 10^{-4} \mathrm{~Pa}$. The effective device area was $0.07 \mathrm{~cm}^{2}$.

Measurements. - Electrochemical properties were examined by cyclic voltammetry. The cyclic voltammograms were performed with a potentiostat/galvanostat (Princeton Applied Research, 273A) in an Ar-bubbled $o$-dichlorobenzene/acetonitrile $=4: 1(\mathrm{v} / \mathrm{v})$ solution containing $0.1 \mathrm{M}$ of tetrabutylammonium tetrafluoroborate as a supporting electrolyte with an $\mathrm{Ag} / \mathrm{Ag}^{+}\left(0.01 \mathrm{M} \mathrm{AgNO}_{3}\right)$ as a reference electrode, a $\mathrm{Pt}$ wire as a counter electrode, and $\mathrm{Pt}$ as a working electrode with an area of $2.0 \mathrm{~mm}^{2}$. The scan rate was set to $50 \mathrm{mV} \mathrm{s}^{-1}$.

The ionization potential of PTQ1 and PCBM was measured with a photoelectron yield spectrometer (Riken Keiki, AC-3). All the neat films (ca. $60 \mathrm{~nm}$ ) were fabricated by spin-coating from each chlorobenzene solution on the ITO substrate. The threshold energy for the photoelectron emission was estimated on the basis of the cubic root of the photoelectron yield plotted against the incident photon energy as reported previously. ${ }^{28}$

The $J-V$ characteristics were measured in a nitrogen atmosphere with a direct current/voltage and current source/monitor (Advantest, R6243) in the dark and under illumination with AM1.5 G simulated solar light at $100 \mathrm{~mW} \mathrm{~cm}{ }^{-2}$. The light intensity was corrected with a calibrated silicon photodiode reference cell (Bunkoh-Keiki, BS520). The active area of the device was $0.07 \mathrm{~cm}^{2}$. The EQE spectra were measured with a digital electrometer (Advantest, R8252) under monochromatic light illumination from a 500-W xenon lamp (Thermo Oriel, 66921) with optical cut filters and a monochromator (Thermo Oriel, Cornerstone). The illumination was carried out from the ITO side under nitrogen atmosphere at room temperature.

Absorption and photoluminescence (PL) spectra were measured with a spectrophotometer (Hitachi, U-3500) and a spectrofluorometer (Horiba Jobin Yvon, FluororLog-3) equipped with a calibrated iHR320 imaging detector, respectively. 


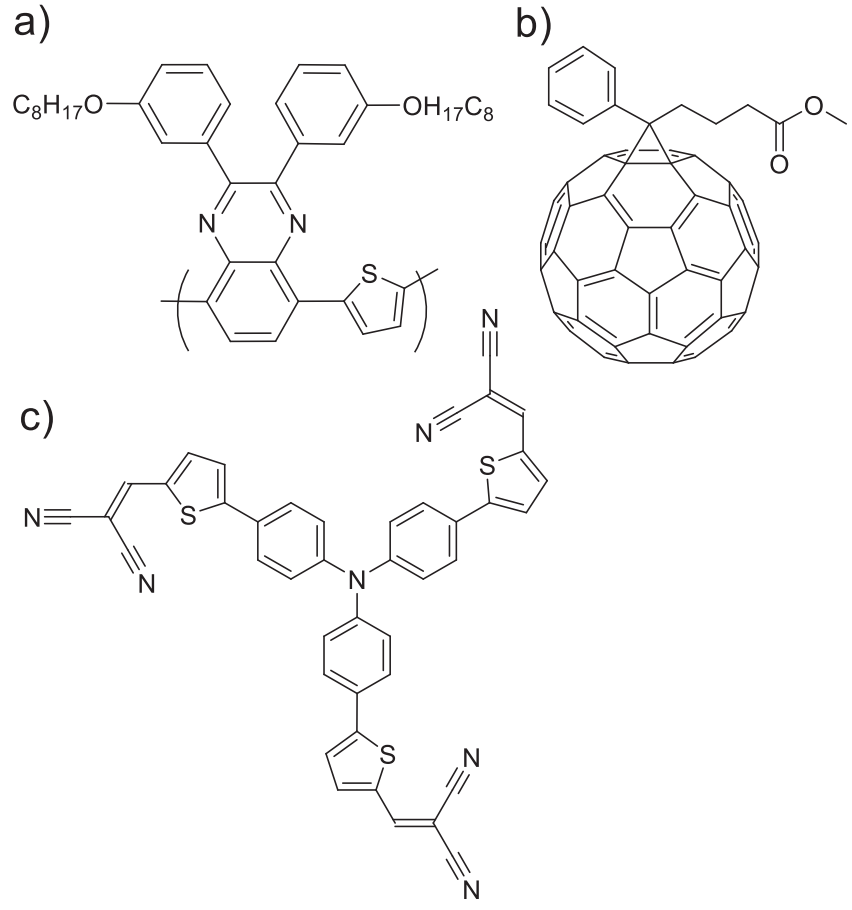

Figure 1. Chemical structures of materials employed in this study: a) PTQ1, b) PCBM, and c) TDCV-TPA.

Contact angles $\theta_{\mathrm{X}}$ of ultrapure water droplets were measured on a spin-coated film of material $X$ at room temperature. The surface energy $\gamma_{X}$ of the material $X$ was evaluated from $\theta_{X}$ by the Neumann's equation combined with Young's equation. The interfacial energy $\gamma_{\mathrm{A}-\mathrm{B}}$ between materials $\mathrm{A}$ and $\mathrm{B}$ was evaluated from $\gamma_{\mathrm{A}}$ and $\gamma_{\mathrm{B}}$ by the Neumann's equation. The wetting coefficient $\omega_{C}$ of material $C$ in a blend of materials A and B was evaluated from the interfacial energies. The details are described elsewhere. ${ }^{15,26}$

\section{Results and Discussion}

Optoelectronic properties.- As shown in Figure 2a, PTQ1 has an absorption band at around $640 \mathrm{~nm}$ and an absorption window at around $500 \mathrm{~nm}$, and TDCV-TPA has an absorption band at around $550 \mathrm{~nm}$. In the PL spectra, PTQ1 and TDCV-TPA have an emission peak at around 730 and $700 \mathrm{~nm}$, respectively. The optical bandgap of PTQ1 was evaluated to be $1.8 \mathrm{eV}$ from the wavelength of intersection between the absorption and PL spectra. On the other hand, the HOMO level was estimated to be $5.1 \mathrm{eV}$ for PTQ1 and $6.2 \mathrm{eV}$ for PCBM by photoemission yield spectroscopy in the solid state and to be $5.5 \mathrm{eV}$ for TDCV-TPA by the cyclic voltammetry. The LUMO level was evaluated to be $3.8 \mathrm{eV}$ for PCBM and $3.4 \mathrm{eV}$ for TDCV-TPA by the cyclic voltammetry and to be $3.3 \mathrm{eV}$ for PTQ1 from the optical bandgap and HOMO level. The energy diagrams of these materials are summarized in Figure 2b.

Figure 3 shows the absorption spectra of PTQ1/PCBM (1:2 w/w) binary and PTQ1/PCBM/TDCV-TPA $(1: 2: 0.1 \mathrm{w} / \mathrm{w})$ ternary blend films. As shown in the figure, the absorption bandwidth (full width at half maximum) is effectively increased from 450 to $600 \mathrm{~nm}$ by a small addition of TDCV-TPA at only one tenth the weight ratio. This is because TDCV-TPA has a large absorption coefficient of 2.5 $\times 10^{5} \mathrm{~cm}^{-1}$ at $550 \mathrm{~nm} \cdot{ }^{27}$ Furthermore, it is noteworthy that there is a large spectral overlap between the PL band of TDCV-TPA and the absorption band of PTQ1. Assuming point dipoles, the Förster radius is estimated to be $3.1 \mathrm{~nm}$ from the spectral overlap with a PL quantum efficiency of $14 \%$ for TDCV-TPA and a molar absorption coefficient of $2.2 \times 10^{4} \mathrm{M}^{-1} \mathrm{~cm}^{-1}$ at $600 \mathrm{~nm}$ of PTQ1. Thus, the energy transfer from TDCV-TPA to PTQ1 would be efficient in the
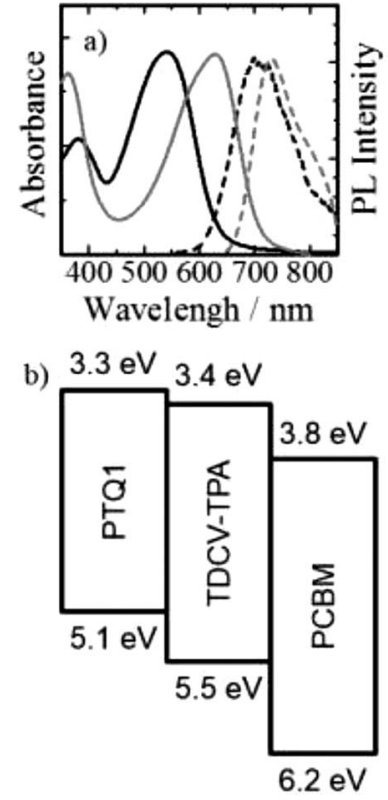

Figure 2. a) Absorption (solid lines) and photoluminescence (broken lines) spectra of PTQ1 (gray lines) and TDCV-TPA (black lines). b) Energy diagram of materials employed in this study. The figures represent the HOMO (lower) and LUMO (upper) energy in electron volts.

blend film as described later. In summary, these two materials are a suitable combination for extending the light-harvesting range because of the complementary absorption bands and for the efficient energy transfer from TDCV-TPA to PTQ1.

Energy and charge transfer- - In order to examine how efficient the energy transfer from TDCV-TPA to PTQ1, we measured the PL spectrum of PTQ1/TDCV-TPA binary blend films excited at $500 \mathrm{~nm}$ where TDCV-TPA has an absorption band as mentioned above. Figure $4 \mathrm{a}$ shows the PL spectra of PTQ1/TDCV-TPA binary blend and TDCVTPA neat films. As shown in the figure, no emission from TDCV-TPA was observed and instead emission from PTQ1 was clearly observed for the PTQ1/TDCV-TPA binary blends even though TDCV-TPA was excited at $500 \mathrm{~nm}$. This result is indicative of quantitative energy transfer from TDCV-TPA to PTQ1: all the TDCV-TPA excitons are efficiently transferred to PTQ1 domains in the blend.

We next consider the possibility of charge transfer from PTQ1 excitons to TDCV-TPA. Figure $4 \mathrm{~b}$ shows the PL spectra of PTQ1/TDCVTPA binary blend and PTQ1 neat films upon the selective excitation of PTQ1 at $630 \mathrm{~nm}$. As shown in the figure, the PTQ1 emission from PTQ1/TDCV-TPA binary blend was comparable to that from the PTQ1 neat film, indicating negligible charge transfer from PTQ1 excitons to TDCV-TPA. This is probably because offset energy in the LUMO levels between PTQ1 and TDCV-TPA is as small as $0.1 \mathrm{eV}$, which would be not enough to break the Coulomb attraction in PTQ1

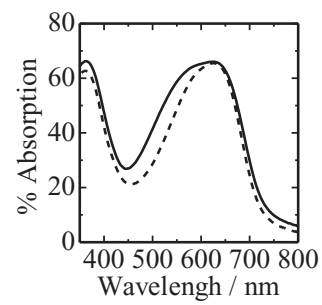

Figure 3. Absorption spectra of PTQ1/PCBM binary (broken line) and PTQ1/PCBM/TDCV-TPA ternary (solid line) blend films. 


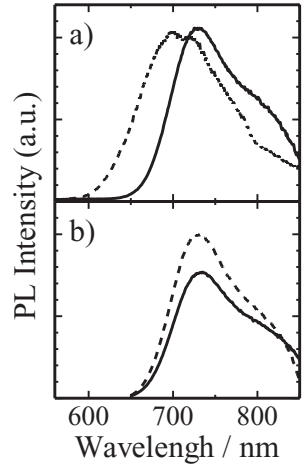

Figure 4. Photoluminescence spectra of a) PTQ1/TDCV-TPA blend (solid line) and TDCV-TPA neat (broken line) films excited at $500 \mathrm{~nm}$, and b) PTQ1/TDCV-TPA blend (solid line) and PTQ1 neat (broken line) films excited at $630 \mathrm{~nm}$.
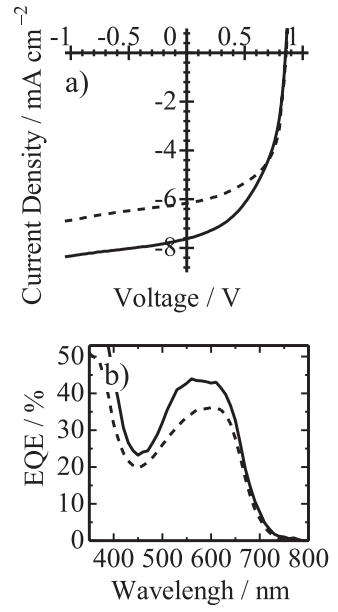

Figure 5. a) $J-V$ characteristics and b) EQE spectra of PTQ1/PCBM binary blend (broken lines) and PTQ1/PCBM/TDCV-TPA ternary blend (solid lines) solar cells.

excitons. In other words, TDCV-TPA does not serve as a quencher for PTQ1 excitons.

Photovoltaic properties. - Figure 5a shows $J-V$ characteristics of PTQ1/PCBM/TDCV-TPA ternary blend and PTQ1/PCBM binary blend solar cells under the simulated solar illumination at $100 \mathrm{~mW}$ $\mathrm{cm}^{-2}$. The device parameters are summarized in Table I. As shown in the figure, the $J_{\mathrm{SC}}$ is significantly improved by more than $20 \%$ from 6.2 to $7.6 \mathrm{~mA} \mathrm{~cm}^{-2}$ even though the addition of TDCV-TPA is as small as $3.2 \mathrm{wt} \%$. This improvement in $J_{\mathrm{SC}}$ is ascribed to the increase in the EQE signals over 500-600 nm as shown in Figure 5b. The bandwidth of the EQE spectrum was larger for the PTQ1/PCBM/TDCV-TPA ternary cell than for PTQ1/PCBM binary blend cell. This is because the absorption bandwidth is extended by addition of TDCV-TPA as mentioned above. We note that there is no change in the open-circuit voltage $\left(V_{\mathrm{OC}}\right)$ between ternary and binary blend solar cells. This finding suggests that TDCV-TPA molecules are not involved in the charge recombination at the heterojunction. Rather, TDCV-TPA molecules are possibly located in PTQ1 or PCBM domains as discussed below.

Table I. Photovoltaic parameters of PTQ1/PCBM/TDCV-TPA ternary and PTQ1/PCBM binary blend solar cells.

\begin{tabular}{ccccc} 
& $J_{\mathrm{SC}} / \mathrm{mA} \mathrm{cm}^{-2}$ & $V_{\mathrm{OC}} / \mathrm{V}$ & $\mathrm{FF}$ & $\mathrm{PCE} / \%$ \\
\hline Ternary & 7.6 & 0.86 & 0.50 & 3.3 \\
Binary & 6.2 & 0.86 & 0.59 & 3.1
\end{tabular}

Table II. Surface energy of materials employed in this study.

\begin{tabular}{cccc} 
& TDCV-TPA & PTQ1 & PCBM \\
\hline$\gamma / \mathrm{mJ} \mathrm{m}^{-2}$ & 23.5 & 26.6 & 30.6
\end{tabular}

Dye location. - Finally, we discuss the location of dye molecules in ternary blend films in terms of surface energy $(\gamma)$. Table II summarizes the surface energy of each material evaluated by the contact angle method. Sumita et al. have studied the location of the third material in polymer/polymer blends in terms of surface energy. ${ }^{26}$ They introduced a key parameter of the wetting coefficient $(\omega)$, which is evaluated from the surface energy of each component material, to predict the location of the third material fillers in polymer/polymer binary blends. We also have shown that the location of dye molecules in polymer/PCBM blends can be predicted on the basis of the wetting coefficient. ${ }^{15}$ The wetting coefficient of TDCV-TPA for PTQ1/PCBM blends is evaluated to be 2.5 , suggesting that TDCV-TPA molecules are likely to be located in PTQ1 domains with a lower surface energy. This is consistent with no change in the $V_{\mathrm{OC}}$ between ternary and binary blend solar cells mentioned above. We therefore conclude that TDCV-TPA molecules are primarily located in PTQ1 domains. In this case, PTQ1 excitons are efficiently generated from TDCVTPA excitons by energy transfer even upon the photoexcitation of TDCV-TPA in the shorter wavelength region, and hence migrate to a PTQ1/PCBM interface to generate charge carriers. Thus, the dye location in low-bandgap polymer domains is the key to success for efficient dye sensitization in the visible region.

\section{Conclusion}

In summary, we have demonstrated a novel approach to improving the photovoltaic performances of binary solar cells based on a lowbandgap polymer PTQ1 and PCBM by incorporating a wide-bandgap molecule TDCV-TPA. As a result, the $J_{\mathrm{SC}}$ is improved by more than $20 \%$ from 6.2 to $7.6 \mathrm{~mA} \mathrm{~cm}^{-2}$ compared to that of the control binary cell. This is because the incorporation of TDCV-TPA can extend the absorption bandwidth to collect much more photons in the visible as well as in the near-IR region. The keys to the improvement are as follows: 1) dye molecules should be located in low-bandgap polymer domains, 2) the PL band of wide-bandgap dye molecules should be well overlapped with the absorption band of low-bandgap polymers to make sure efficient energy transfer from the dye to the matrix polymer, and 3) polymer excitons should not be quenched by incorporating dye molecules. For the selective dye loading to low-bandgap polymer domains, the surface energy of wide-bandgap molecules should be lower than that of low-bandgap polymer and PCBM. This requirement is different from that for near-IR dye molecules into the heterojunction. Thus, this approach is compatible with near-IR dye sensitization. We therefore propose that it would be useful for further improvements to employ wide-bandgap and near-IR dye molecules at the same time in low-bandgap polymer solar cells in order to extend the light-harvesting range from visible to near-IR region.

\section{Acknowledgments}

This work was partly supported by the FIRST program (Development of Organic Photovoltaics toward a Low-Carbon Society: Pioneering Next Generation Solar Cell Technologies and Industries via Multi-manufacturer Cooperation) and the JST PRESTO program (Photoenergy Conversion Systems and Materials for the Next Generation Solar Cells). Y. Wang is sponsored by the China Scholarship Council (CSC).

\section{References}

1. M. C. Scharber and N. S. Sariciftci, Prog. Polym. Sci., 38, 1929 (2013).

2. N. Yeh and P. Yeh, Renew. Sust. Energy Rev., 21, 421 (2013). 
3. L. Dou, J. You, Z. Hong, Z. Xu, G. Li, R. A. Street, and Y. Yang, Adv. Mater, 25, 6642 (2013).

4. J. You, L. Dou, K. Yoshimura, T. Kato, K. Ohya, T. Moriarty, K. Emery, C. C. Chen, J. Gao, G. Li, and Y. Yang, Nat. Commun., 4, 1446 (2013).

5. M. A. Green, K. Emery, Y. Hishikawa, W. Warta, and E. D. Dunlop, Prog. Photovolt: Res. Appl., 22, 1 (2014).

6. P. M. Beaujuge and J. M. J. Frechet, J. Am. Chem. Soc., 133, 20009 (2011).

7. C. Duan, F. Huang, and Y. Cao, J. Mater. Chem., 22, 10416 (2012).

8. L. Bian, E. Zhu, J. Tang, W. Tang, and F. Zhang, Prog. Polym. Sci., 37, 1292 (2012).

9. E. Zhou, K. Hashimoto, and K. Tajima, Polymer, 54, 6501 (2013).

10. T. Xu and L. Yu, Mater. Today, 17, 11 (2014).

11. S. Honda, T. Nogami, H. Ohkita, H. Benten, and S. Ito, ACS Appl. Mater. Interfaces, 4, 804 (2009).

12. Y. A. M. Ismail, T. Soga, and T. Jimbo, Sol. Energy Mater. Sol. Cells, 93, 1582 (2009).

13. M. Koppe, H. J. Egelhaaf, G. Dennler, M. C. Scharber, C. J. Brabec, P. Schilinsky, and C. N. Hoth, Adv. Funct. Mater, 20, 338 (2010).

14. S. Honda, H. Ohkita, H. Benten, and S. Ito, Chem. Commun., 46, 6596 (2010).

15. S. Honda, H. Ohkita, H. Benten, and S. Ito, Adv. Energy Mater, 1, 588 (2011).

16. J. W. Choi, C. Kulshreshtha, G. P. Kennedy, J. H. Kwon, S. H. Jung, and M. Chae, Sol. Energy Mater. Sol. Cells, 95, 2069 (2011).
17. S. Honda, S. Yokoya, H. Ohkita, H. Benten, and S. Ito, J. Phys. Chem. C, 115, 11306 (2011).

18. T. Ameri, J. Min, N. Li, F. Machui, D. Baran, M. Forster, K. J. Schottler, D. Dolfenm, U. Scherf, and C. J. Brabec, Adv. Energy Mater, 2, 1198 (2012).

19. L. Yang, H. Zhou, S. C. Price, and W. You, J. Am. Chem. Soc., 134, 5432 (2012).

20. P. P. Khlyabich, B. Burkhart, and B. C. Thompson, J. Am. Chem. Soc., 134, 9074 (2012).

21. T. Ameri, P. Khoram, J. Min, and C. J. Brabec, Adv. Mater, 25, 4245 (2013).

22. G. Grancini, R. S. S. Kumar, M. Maiuri, J. Fang, W. T. S. Huck, M. J. P. Alcocer, G. Lanzani, G. Cerullo, A. Petrozza, and H. J. Snaith, J. Phys. Chem. Lett., 4, 442 (2013).

23. L. Yang, L. Yan, and W. You, J. Phys. Chem. Lett., 4, 1802 (2013).

24. H. Xu, T. Wada, H. Ohkita, H. Benten, and S. Ito, Electrochim. Acta, 100, 214 (2013).

25. H. Xu, H. Ohkita, H. Benten, and S. Ito, Jpn. J. Appl. Phys., 53, $01 \mathrm{AB} 10$ (2014).

26. M. Sumita, K. Sakata, S. Asai, K. Miyasaka, and H. Nakagawa, Polym. Bull., 25, 265 (1991).

27. K. Sulaiman and M. S. Fakir, Thin Solid Films, 519, 5219 (2011).

28. S. Yamamoto, A. Orimo, H. Ohkita, H. Benten, and S. Ito, Adv. Energy Mater., 2, 229 (2012). 